\title{
Left ventricle geometry, atrial strain, ventricle strain and hemodynamics across aortic valve before and after transcatheter aortic valve replacements
}

\author{
Aslannif Roslan ${ }^{1}$, YEE SIN TEY ${ }^{1}$, Faten Aris A ${ }^{1}$, Afif Ashari ${ }^{1}$, Abdul Shaparudin A ${ }^{1}$, \\ Wan Faizal Rahimi Shah W ${ }^{1}$, Koh Hui Beng ${ }^{1}$, Lee Tjen Jhung ${ }^{1}$, Ahmad Tantawi Jauhari \\ Aktifanus $^{1}$, Jayakhanthan Kolanthaivelu ${ }^{1}$, Kumara Gurupparan Ganesan ${ }^{1}$, and Shaiful \\ Azmi Yahaya ${ }^{1}$ \\ ${ }^{1}$ Institute Jantung Negara Sdn Bhd
}

January 16, 2022

\begin{abstract}
Background: Transcatheter Aortic Valve Replacements (TAVR) has become widespread throughout the world. To date there are no echocardiographic study of TAVR patients from Southeast Asia (SEA). We sought to evaluate 1) changes in echocardiographic and strain values pre and post TAVR 2) relationship between aortic stenosis (AS) severity and strain values, 3) left ventricle geometry in severe AS 4) relationship of flow rate to dimensionless index (DVI) and acceleration time (AT) and 5) effect of strains on outcome. Methods: Retrospective study of 112 TAVR patients in our center from 2009 to 2020. The echocardiographic and strain images pre (within 1 months), post (day after) and 6 months post TAVR were analyzed by expert echocardiographer. Results: The ejection fraction (EF) increased at 6 months $(53.02 \pm 12.12 \%$ to $56.35 \pm 9.00 \%)(\mathrm{p}=0.044)$. Interventricular septal thickness in diastole (IVSd) decreased $(1.27 \pm 0.21 \mathrm{~cm}$ to $1.21 \pm 0.23 \mathrm{~cm})(\mathrm{p}=0.038)$ and left ventricle internal dimension in diastole (LVIDd) decreased from $4.77 \pm 0.64 \mathrm{~cm}$ to $4.49 \pm 0.65 \mathrm{~cm}(\mathrm{p}=0.001)$. No changes in stroke volume index (SVI pre vs 6 months p $=0.187)$, but the flow rate increases $(217.80 \pm 57.61 \mathrm{mls} / \mathrm{s}$ to $251.94 \pm 69.59 \mathrm{mls} / \mathrm{s}, \mathrm{p}<0.001)$. Global Longitudinal Strain (GLS) improved from $-11.44 \pm 4.23 \%$ to $-13.94 \pm 3.72 \%$ (p <0.001), Left Atrial Reservoir strain (Lar-S) increased from $17.44 \pm 9.16 \%$ to $19.60 \pm 8.77 \%(\mathrm{p}=0.033) .8$ patients $(7.5 \%)$ had IVSd $<1.0 \mathrm{~cm}$, and 4 patients $(3.7 \%)$ had normal left ventricle (LV) geometry. There was linear relationship between IVSd and mean PG $(\mathrm{r}=0.208, \mathrm{p}=0.031)$, between GLS to aortic valve area (AVA) and aortic valve area index (AVAi) $(\mathrm{r}=-0.305, \mathrm{p}=0.001$ and $\mathrm{r}=-0.316, \mathrm{p}=0.001)$. There was also relationship between AT $(r=-0.20, p=0.04)$ and DVI $(r=0.35, p<0.001)$ with flow rate. Patients who died late (after 6 months) had lower GLS at 6 months. (Alive; $-13.94 \pm 3.72 \%$ vs Died; $-12.43 \pm 4.19 \%, \mathrm{p}=0.001$ ) Conclusion: At 6 months TAVR cause reverse remodeling of the LV with reduction in IVSd, LVIDd and improvement in GLS and LAr-S. There is linear relationship between GLS and AVA and between IVSd and AVA.
\end{abstract}

\section{Hosted file}

Left ventricle geometry, atrial strain, ventricle strain and hemodynamics across aortic valve before a available at https://authorea.com/users/455662/articles/552944-left-ventricle-geometryatrial-strain-ventricle-strain-and-hemodynamics-across-aortic-valve-before-and-aftertranscatheter-aortic-valve-replacements 
Figure 1 (a). Relationship between pre IVSd with pre mean PG, pre-AVA and pre AVAi
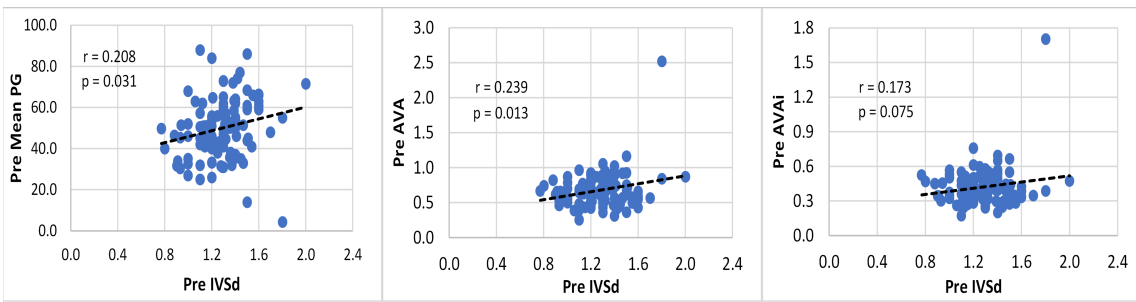

Figure 1 (c). Relationship between pre-LAr-S with pre mean PG, pre-AVA and pre AVAi
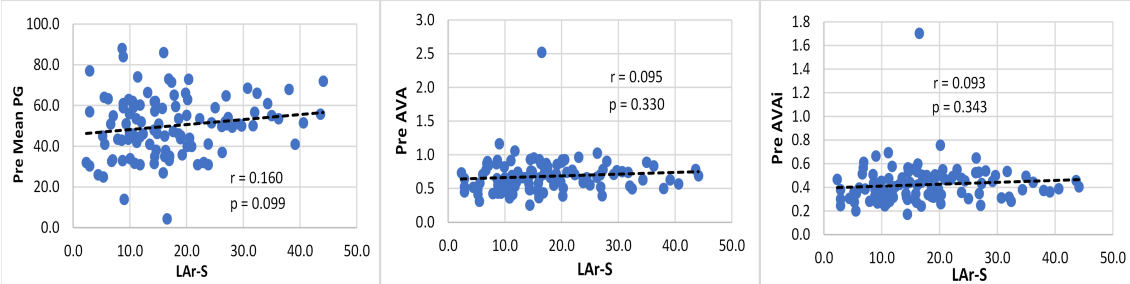

Figure 1 (d). Relationship between pre RVFW-S with pre mean PG, pre-AVA and pre AVA
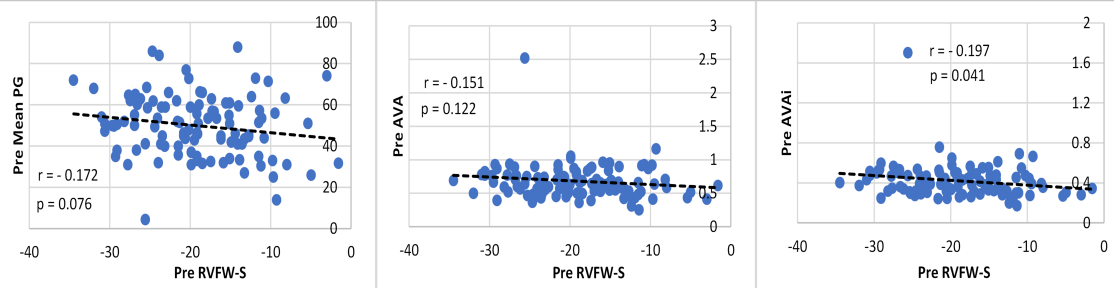

Figure 1 (b). Relationship between pre GLS with pre mean PG, pre-AVA and pre AVAi

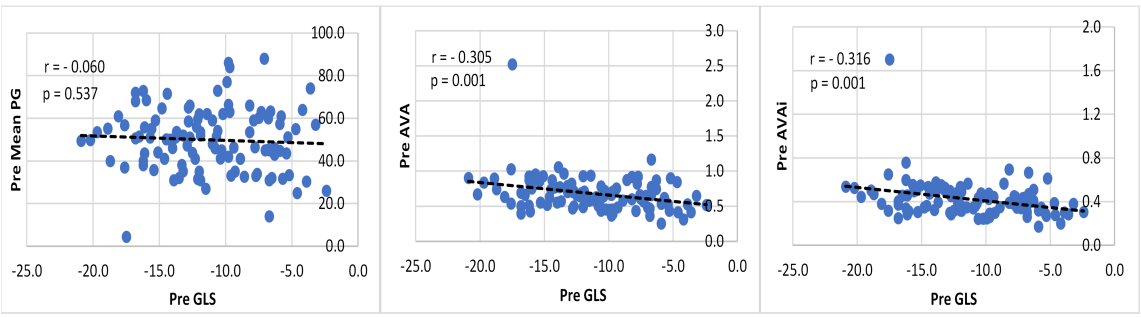

Figure 2. Relationship between DVI/AT and Flow rate
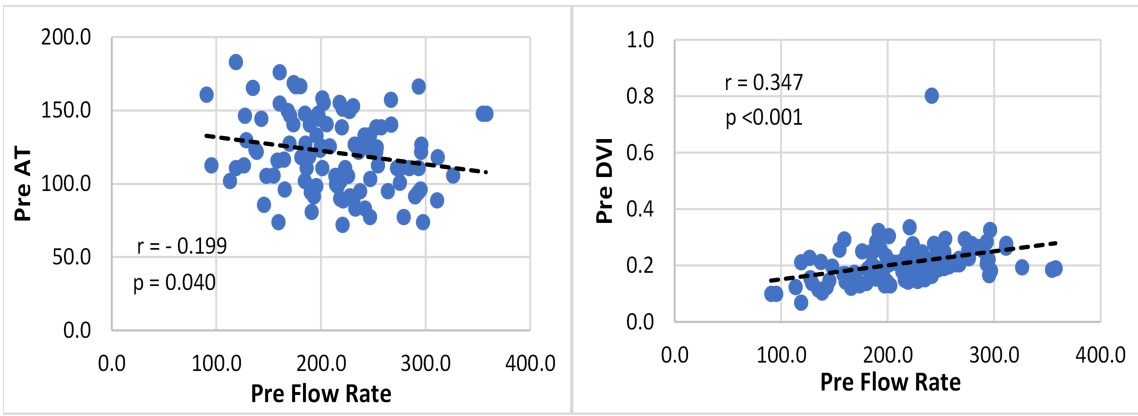

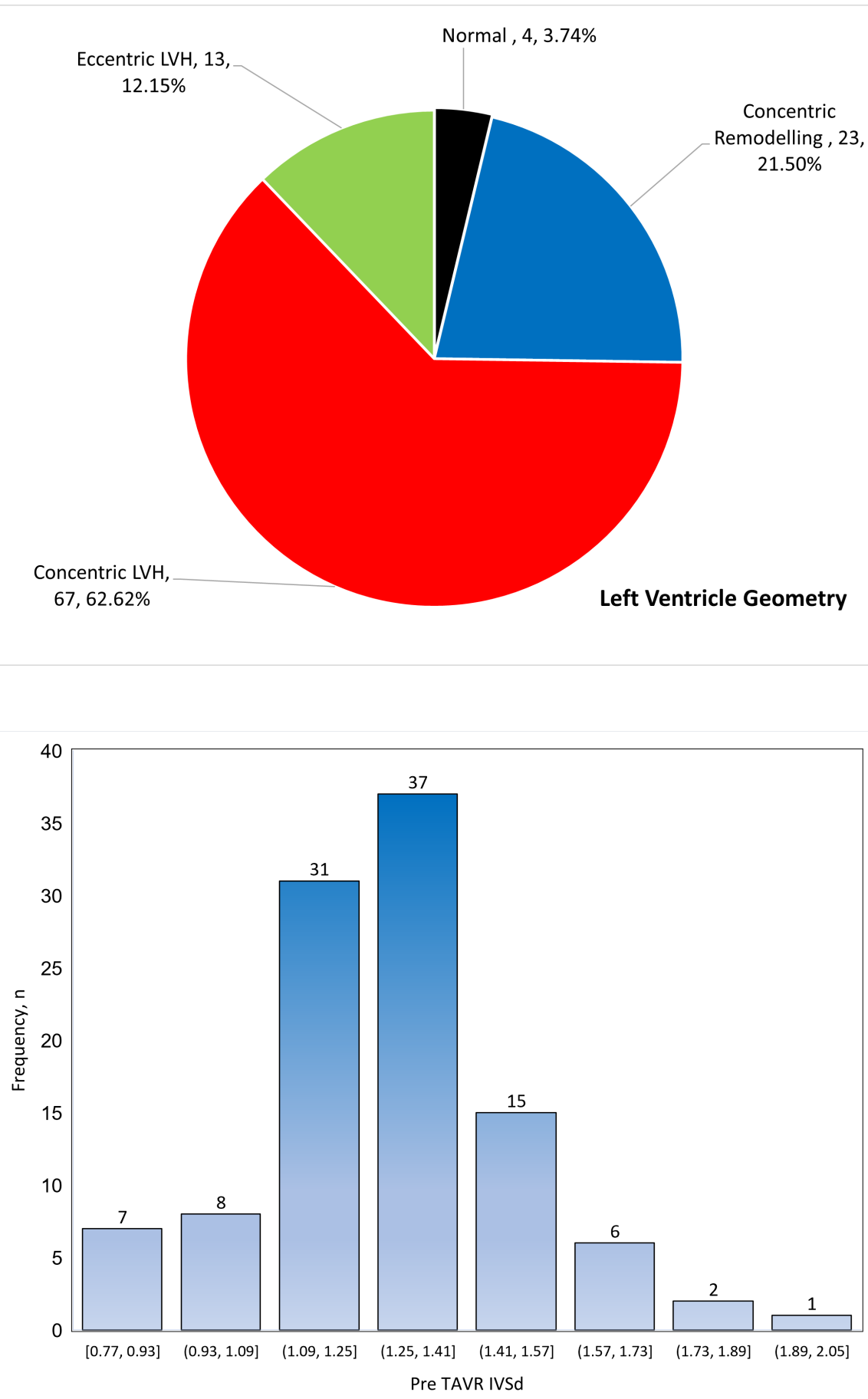


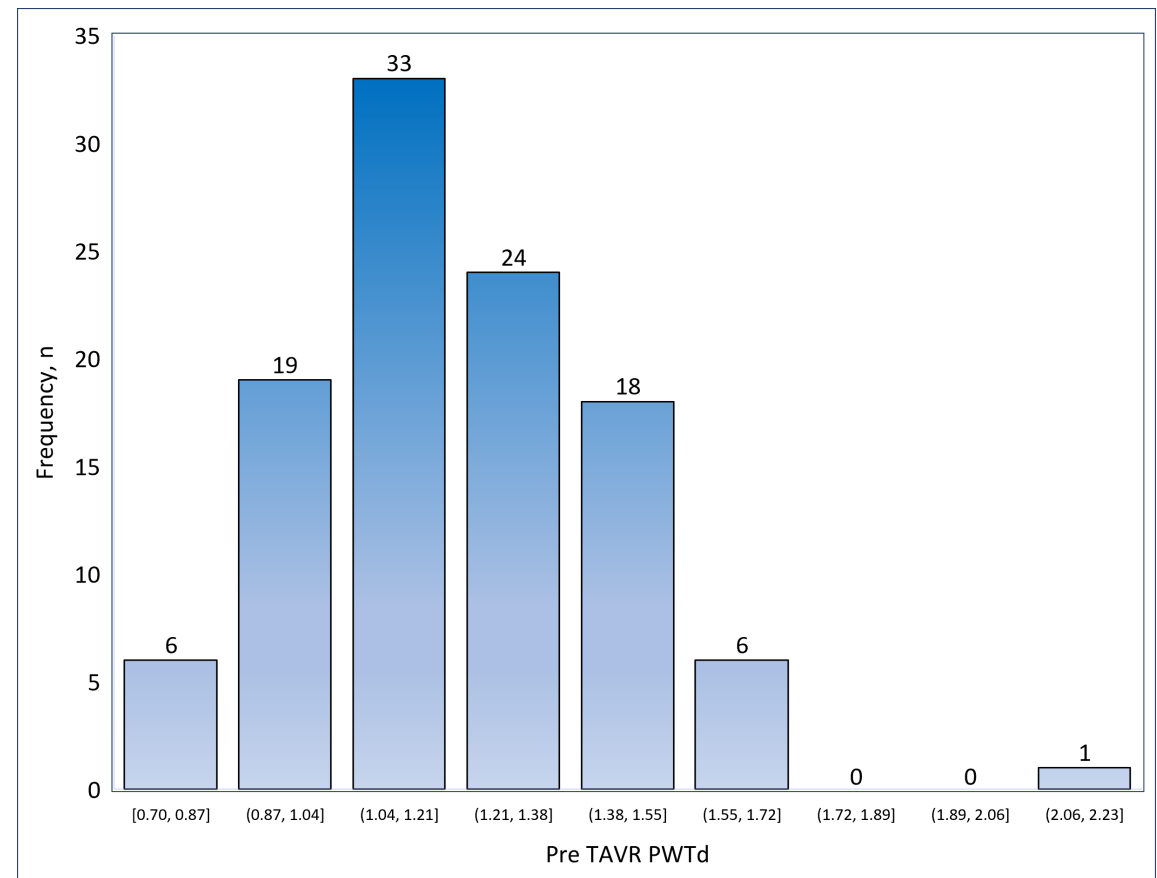

\section{Hosted file}

Tables.pptx available at https://authorea.com/users/455662/articles/552944-left-ventriclegeometry-atrial-strain-ventricle-strain-and-hemodynamics-across-aortic-valve-before-andafter-transcatheter-aortic-valve-replacements 